\title{
Legislative Success in the Arkansas General Assembly: A Causal Perspective
}

\section{Mark C. Ellickson, Southwest Missouri State University}

Donald E. Whistler, University of Central Arkansas

This study employs recursive path analysis techniques to develop a causal model of legislative success in the "one party-no party" state legislature of Arkansas. Utilizing a unique fivestep process to measure bill-passage through the Arkansas House, four direct paths to legislative success were identified: educational level, age, race, and seniority. The final model suggests a legislative body in transition from amateur status and exclusivity to one more autonomous and competitive.

\section{Introduction}

The main task of state legislatures involves passing bills into law. Approximately 250,000 bills are introduced every biennium, and nearly one-fifth are enacted into law (Book of the States 1990). Recognizing the paramount importance of the legislative function, political scientists have long sought to identify those factors which facilitate the passage of legislation. Identification of the determinants of legislative success is necessary if political scientists are to understand and predict legislative behavior and output; it is necessary for citizens who want to elect effective representatives who can best serve their interests; and it is necessary for legislators themselves who wish to serve their constituents in an effective manner.

Regrettably, studies that use state legislators as units of analysis in an attempt to integrate the diverse and disparate findings of this field into a theory of legislative success have largely failed. Aside from Meyer's (1980) causal analysis of the 1973 North Carolina state legislature, there have been no further attempts at model building in this area of study. Furthermore, legislative studies that do exist have tended to 1) emphasize bivariate statistical designs (as opposed to multivariate); 2) examine "reputation" for influence rather than "actual" legislative success; and 3) focus on two-party or modified one-party dominant state legislatures.

This article seeks to address these gaps in the literature by utilizing recursive path analysis techniques to develop a causal model of 1egislative success in the "one party-no party" state legislature of Ar- 
kansas. ${ }^{1}$ In addition, legislative success will be measured directly using a relatively new method we believe to be an improvement over previous efforts.

\section{Literature Review and Model Development}

A review of the literature on the determinants of legislative success revealed three comprehensive categories: personal, institutional, and environmental. ${ }^{2}$ With respect to personal attributes, a number of studies indicated that education, occupation, age, gender, race, and political ideology were likely contributors to a legislator's success (or lack of it) in bill passage. For example, better educated legislators should be able to communicate more clearly within the legislative arena, and to grasp complex issues and formulate solutions to problems more readily than their less educated colleagues (Meyer 1980; Rosenthal 1981, 57-60; Weissert 1988; Rosenthal 1989, 75-76). Legislators with prestigious occupations may enjoy a higher esteem among colleagues (Meyer 1980). Attorneys, in particular, may be advantaged because of their training in an area (bill drafting) essential to the legislative process (Weissert 1988). ${ }^{3}$

Legislative performance and its relationship to age is unclear. Some argue that the relationship is curvilinear in nature (Weissert 1988). Here a legislator's success is thought to increase with age and then decline as energy levels decrease and issue stands become anachronistic. Others argue that the relationship is negative. They cite the professionalization of state legislatures in recent decades as creating a window of opportunity for junior members to make a "name" for themselves early in their careers (Rosenthal 1981, 31, 57-59; Ellickson and Whistler 1989, 16).

Evidence regarding the impact of race and gender on legislative success is limited and conflicting. While several studies have discerned no significant differences in legislative success based on race or gender (Hamm, Harmel, and Thompson 1983; Thompson and Moncrief 1990), others have noted the dearth of women and blacks in many state houses (Rosenthal 1981, 30-31). Because representatives of these groups are likely to have less seniority and expertise and to hold fewer leadership positions than white male representatives, we would expect them also to be less successful in the legislature.

Finally, the pervasiveness of conservatism among southern state legislators suggests that success should accrue to those holding conservative views (Wolfinger and Hollinger 1970; Meyer 1980). 
The literature also indicated that institutional variables may be important determinants of legislative behavior. Serving the legislature in a formal capacity (i.e., party leadership position and/or committee leadership role) is evidence of legislative involvement and value to the legislature (Best 1971; Frantzich 1979). Party leaders have access to numerous sources of informal power (Rosenthal 1981), and thus greater potential for success in the legislature (Meyer 1980). Similarly, prestigious committee assignments can allow legislators to become leading experts on select subjects, thereby enhancing their special status among colleagues (Wahlke, Eulau, Buchanan, and Ferguson 1962; Smith and Deering 1984; Sinclair 1986).

Seniority is another institutional characteristic often associated with legislative success. In a tradition-laden institution such as the legislature, seniority provides a rough but apt indicator of political experience, achievement, and accumulated wisdom--all plausible contributors to success (Frantzich 1979; Meyer 1980; Squire 1988).

A final subset of attributes concerns the environmental constraints within which legislators must operate. Geographic and urbanrural differences may generate political issues which enhance or detract from a legislator's standing in the legislature. For example, there is a longstanding historical schism between the northwest hill region of Arkansas and the delta lowlands (Ledbetter 1972, 16-18; Hinshaw 1986). The pre-Civil War delta plantation culture supported the war, while the non-slaveholding mountain and hill counties in northwest Arkansas opposed it and ultimately developed into a hotbed of populism after the war (Key 1949, 5-8; Bass and DeVries 1976, 88; Hinshaw 1986). This heterogeneous mix of mountain and delta populations has resulted in separate and distinct constituencies within the Arkansas General Assembly (Griffin 1971, 17), although Savage and Blair (1984, 59-85) believe that this geographic division may have lessened somewhat in recent years.

A second environmental factor, urban-rural district representation, has historically been a major source of legislative conflict (Jewell 1964; Francis 1967). Despite the reapportionment movement of the 1960 s, rural power has been slow to dissipate in some southern states (see Tickamyer 1983). Indeed, Arkansas itself has a long history of intense urban-rural conflict in the legislature (Francis 1967,41) and has frequently pursued the strategy of placing rural conservative Democrats in key leadership positions to perpetuate rural influence (Saffell 1987, 122). Hence, we would anticipate rural legislators in Arkansas to be 
more effective than those from urban districts.

These factors by no means exhaust the list of attributes which may affect a legislator's ability to secure passage of his or her legislation. Policy expertise, political friendship and trust, strength of local interest groups, level of district competition, and the internal organization of a legislature have all been cited as possible factors in any model of legislative effectiveness (see Rosen 1974; Meyer 1980; Caldeira and Patterson 1988; Squire 1988). Unfortunately, the arduousness of data collection and the desirability of model parsimony require the selective incorporation of a limited number of variables in any research project.

With respect to our dependent variable, legislative success, most earlier studies used reputational measures based on "perceptions of influence" (see Francis 1962; Best 1971; Meyer 1980). Dahl (1976) and others have criticized the reputational approach on the grounds that potential for influence does not necessarily result in actual success. Consequently, more recent studies have sought to measure legislative success directly (see Frantzich 1979; Hamm et al. 1983; Ellickson and Whistler 1989). Here the operational focus is on a lawmaker's ability to convert his or her legislation into law. The assertion is made that success is not identifiable until a legislator's preferences on important decisions prevail on a regular basis (Dahl 1961). In this study we will utilize the direct measurement approach and will incorporate "reputation for influence" as an intervening variable in our model of legislative success.

Guided by the literature on legislatures, a descriptive model illustrating presumed causal relationships among major variables was constructed. As shown in Figure 1 below, personal and environmental factors are treated as determinants of seniority, formal office, reputation, and legislative success. Additionally, institutional status variables and reputation for influence are viewed as causal forces on legislative success.

\section{Research Design: Setting and Measurements}

The units of analysis in this study were all Democratic legislators in the 1981 session of the Arkansas House of Representatives. ${ }^{4}$ Specific measures regarding personal, institutional, and environmental attributes are contained in Appendix A. Data regarding reputation for influence were obtained through interviews with 84 of 100 House members..$^{5}$ The survey questionnaire included the following question:

"If you were to name four or five legislators who are most effective at getting bills passed, whom would you name?" 


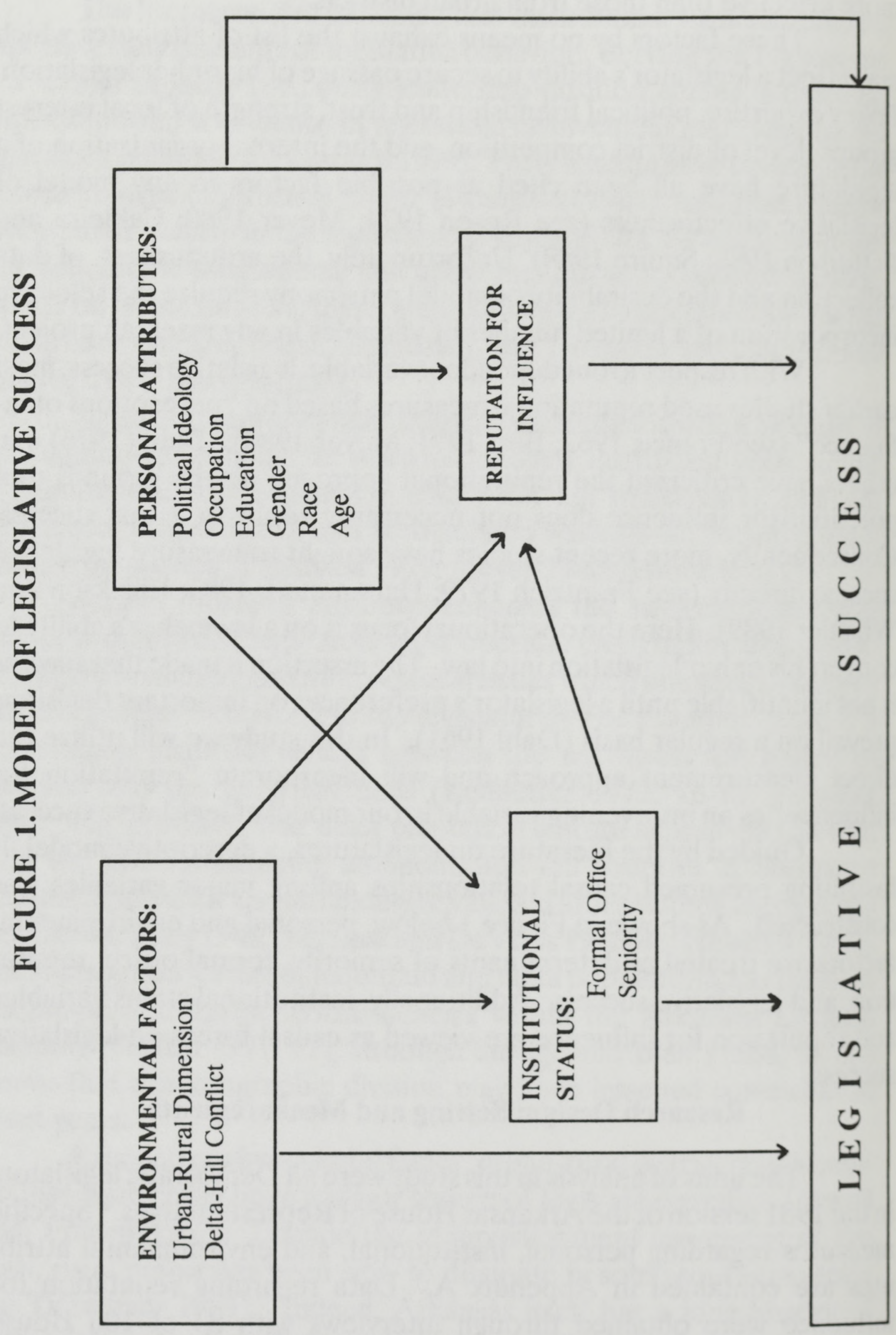


House members were ranked from highest to lowest based upon the number of mentions given to individual representatives.

To measure our dependent variable, legislative success, we observed how successful a legislator was at getting his or her bills passed through the House chamber. ${ }^{6}$ In a previous study, twenty-six legislative maneuvers leading to bill passage in the Arkansas legislature were identified (see Whistler and Ellickson 1988). This coding scheme was modified by combining similar legislative maneuvers to identify the five major legislative steps necessary for bill passage in the Arkansas House chamber (see Appendix B). Bill-passage success for each legislator was then calculated by "scoring" each bill submitted according to the index in Appendix B and totalling the results. ${ }^{7}$ For example, legislator A submits six bills: two bills never make it out of committee (1 point each), one bill is debated on the House floor, but receives no further action (2 points), one bill is defeated on the House floor ( 3 points), and two bills pass the House chamber with minimal formal legislative maneuvering ( 5 points each). Legislator $\mathrm{A}$, then, is accorded 17 points using this procedure. ${ }^{8}$

This system of measurement rewards those legislators who submit a large quantity of bills (active) and who are successful at maneuvering them through the five-step process described above (productive). Other legislators can score moderately well if they are active or productive. Those who are neither active nor productive should receive low scores under this system of evaluation.

The distribution of bills on this five-point index, displayed in Table 1, indicated that approximately 30 percent of the bills introduced were disposed of very early in the legislative process. Nearly 60 percent of bills introduced into the House chamber were passed successfully, with 36 percent doing so with little or no formal legislative maneuvering. This rather high bill-passage success rate reflects the "politics of accommodation" characteristic of one party-no party state legislatures (Rosenthal 1981, 258-259).

Unlike previous efforts to measure legislative success directly by examining bill activity (Olson and Nonidez 1972; Hamm et al. 1983) or bill productivity (Francis 1962; Frantzich 1979), this approach emphasizes the importance of both bill activity and bill productivity in a single measure. We believe this two-dimensional approach to be an improvement over current one-dimensional designs. 
Table 1. Distribution of Bills On Five-Point Index in the Arkansas House (1981)*

\begin{tabular}{lcr}
\hline Five-Point Index & \multicolumn{2}{c}{$\begin{array}{c}\text { 1980 Lislative Session } \\
\%\end{array}$} \\
\hline 1 (Minimum legislative Success) & 28.8 & $(235)$ \\
2 & 8.0 & $(65)$ \\
3 & 3.3 & $(27)$ \\
4 & 23.7 & $(194)$ \\
5 (Maximum legislative success) & $\underline{36.2}$ & $\frac{(296)}{\mathrm{N}=817}$ \\
\hline
\end{tabular}

- See Appendix B for details of the index.

\section{Meeting Assumptions and Model Estimation}

Intercorrelations among the exogenous variables were examined to determine if multicollinearity was a problem. Even though there is no agreement as to what constitutes substantial correlation among independent variables (Pedhazur 1982, 232-233), the common practice of using bivariate correlations of .75 or higher as a benchmark (Asher 1983 , 52) suggested multicollinearity was not a problem. A more stringent test for collinearity advocated by Lewis-Beck (1980, 59-61) involved regressing each independent variable on all remaining independent variables. In doing so, we found the largest coefficient of multiple determination $\left(\mathrm{R}^{2}\right)$ to be .48 . Thus, we were satisfied that multicollinearity was not a problem in this study.

An inspection of scattergrams indicated that the relationships between each variable and legislative success were approximately linear. Several variables were recoded so that they were normally distributed, while gender (male, female), race (black, white), and political ideology (liberal, conservative) were coded as dummy variables. Finally, it was assumed that the residual "error" terms were uncorrelated and that the causal paths involved no reciprocal causation. We recognize the perils of the uncorrelated error term assumption. ${ }^{9}$ We also recognize the trade-off of reaching erroneous conclusions versus the value of achieving a reasonably clear and simple model.

Analysis of the Arkansas House model proceeded in two steps. First, based on the review of the literature and analysis of the zero-order correlation matrix (for all variables), an initial model in the form of an 
arrow diagram was constructed. Variables with insignificant correlations $(p>.05)$ to any of the endogenous variables were eliminated. Then by applying the Simon-Blalock technique of observing where linkages between pairs of variables had been omitted and generating predictions concerning certain partial correlation coefficients, the model was eventually fully trimmed (Blalock 1964, 61-94). The "final" model is represented by the arrow diagrams and structural equations in Figure 2.

Figure 2. Arkansas House Model (Democrats) with Residual

Variables and Structural Equations*

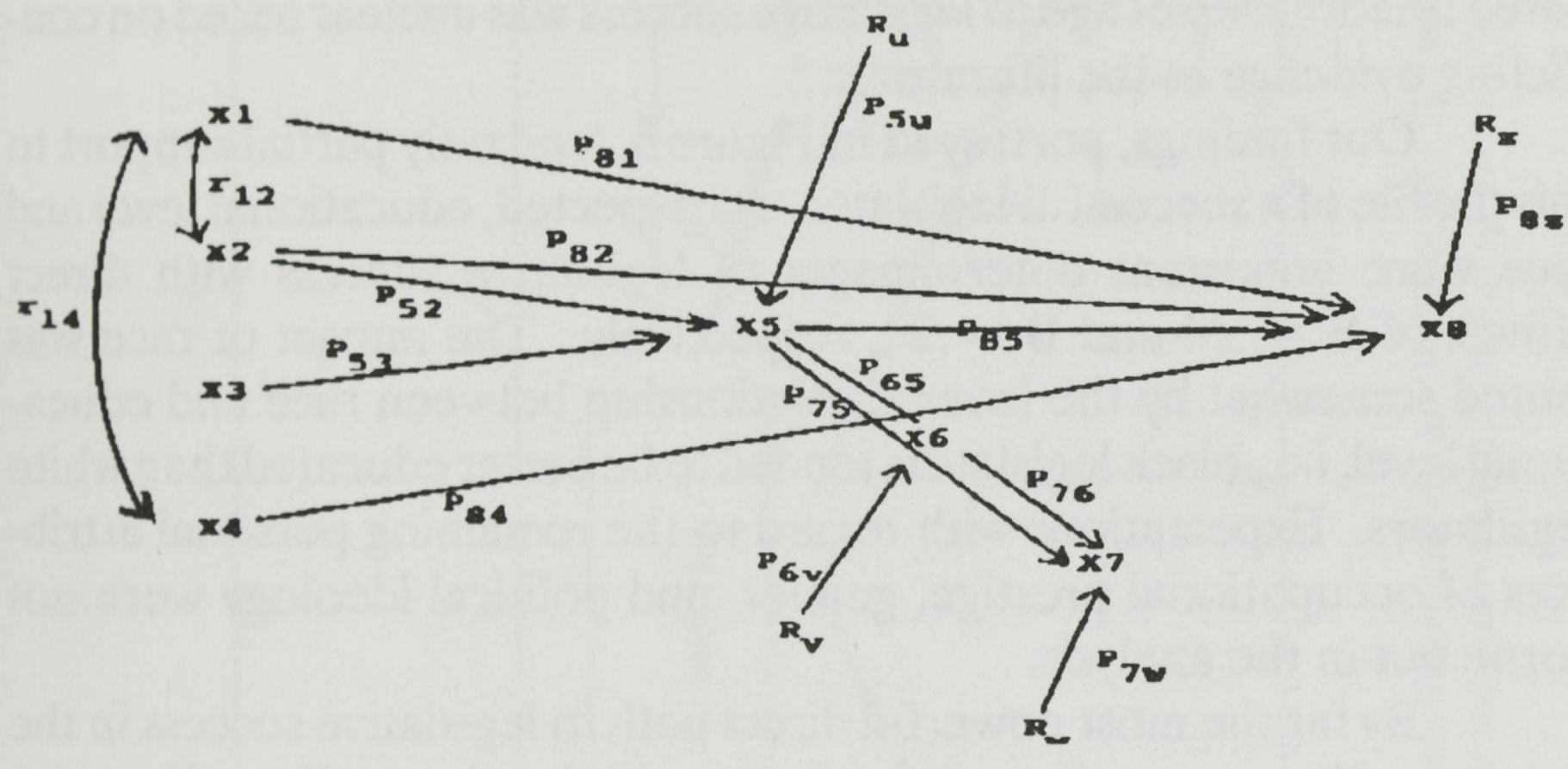

(1) $\mathrm{X}_{5}=\mathrm{P}_{52} \mathrm{X}_{2}+\mathrm{P}_{53} \mathrm{X}_{3}+\mathrm{P}_{5 \mathrm{u}} \mathrm{R}_{\mathrm{u}}$

(2) $X_{6}=P_{65} X_{5}+P_{6 v} R_{v}$

(3) $X_{7}=P_{75} X_{5}+P_{76} X_{6}+P_{7 w} R_{w}$

(4) $X_{8}=P_{81} X_{1}+P_{82} X_{2}+P_{84} X_{4}+P_{85} X_{5}+P_{8 z} R_{Z}$

*Assumes standardized data and uncorrelated residuals.

NOTE: The double-headed arrows reflect correlations among exogenous variables and should not be interpreted as causal arrows.

KEY: $\quad \mathrm{X}_{1}$ (Education); $\mathrm{X}_{2}$ (Age); $\mathrm{X}_{3}$ (Delta-Hill); $\mathrm{X}_{4}$ (Race); $\mathrm{X}_{5}$ (Seniority); $\mathrm{X}_{6}$ (Formal Office); $\mathrm{X}_{7}$ (Reputation); and $\mathrm{X}_{8}$ (Legislative Success)

Second, once the model was trimmed, recursive path analysis was used to estimate the magnitude of the linkages between variables. ${ }^{10}$ To obtain estimates of the main path coefficients, each endogenous variable was regressed on those variables that directly impinged upon it. These path coefficients were then used to examine the underlying causal 
processes within the Arkansas House and to estimate the relative importance of alternative paths of influence/effectiveness. ${ }^{11}$ The model (with direct and indirect effects) is depicted in Figure 3.

\section{Findings}

Figure 1 had predicted that legislative success of Arkansas House Democrats would be enhanced by the characteristics of being a well educated white male with a prestigious occupation; by being a representative from a rural agricultural district in the delta; by being conservative; and by having seniority, a formal position within the legislature, and professional respect from one's colleagues. The anticipated relationship of age to legislative success was unclear based on conflicting evidence in the literature.

Our findings, portrayed in Figure 3, lend only partial support to this profile of a successful legislator. As expected, educational level and race were important determinants of legislative success with direct effects of $B=.24$ and $B=.21$, respectively. The impact of race was muted somewhat by the inverse relationship between race and educational level, i.e., black legislators tended to be better educated than white legislators. Expectations with regard to the remaining personal attributes of occupational prestige, gender, and political ideology were not borne out in the analysis.

By far the most powerful direct path to legislative success in the Arkansas House was through seniority, with its direct effect $(B=.40)$ nearly twice that of any other variable. In a one party-no party legislature, without political parties to channel conflict, we are not surprised to find legislative success so heavily dependent upon personal accumulation of years of service. Likewise, we are not surprised at the powerful impact of seniority on formal position in the legislature $(B=.64)$ and reputation for effectiveness. While seniority had a slightly weaker direct effect on "reputation" than did formal office $(B=.31$ vs. $B=.35$, respectively), it had a substantially greater total effect $(B=.53$ vs. $B=.35$, respectively). These findings are similar to those reported in the Meyer (1980) study.

Interestingly, age was a variable whose impact was felt both directly $(\mathrm{B}=-.24)$ and indirectly $(\mathrm{B}=.22)$ via seniority. As expected, older legislators were associated with greater years of service in the legislature which, in turn, operated directly on legislative success. Younger representatives, however, benefited from a direct path to legislative 


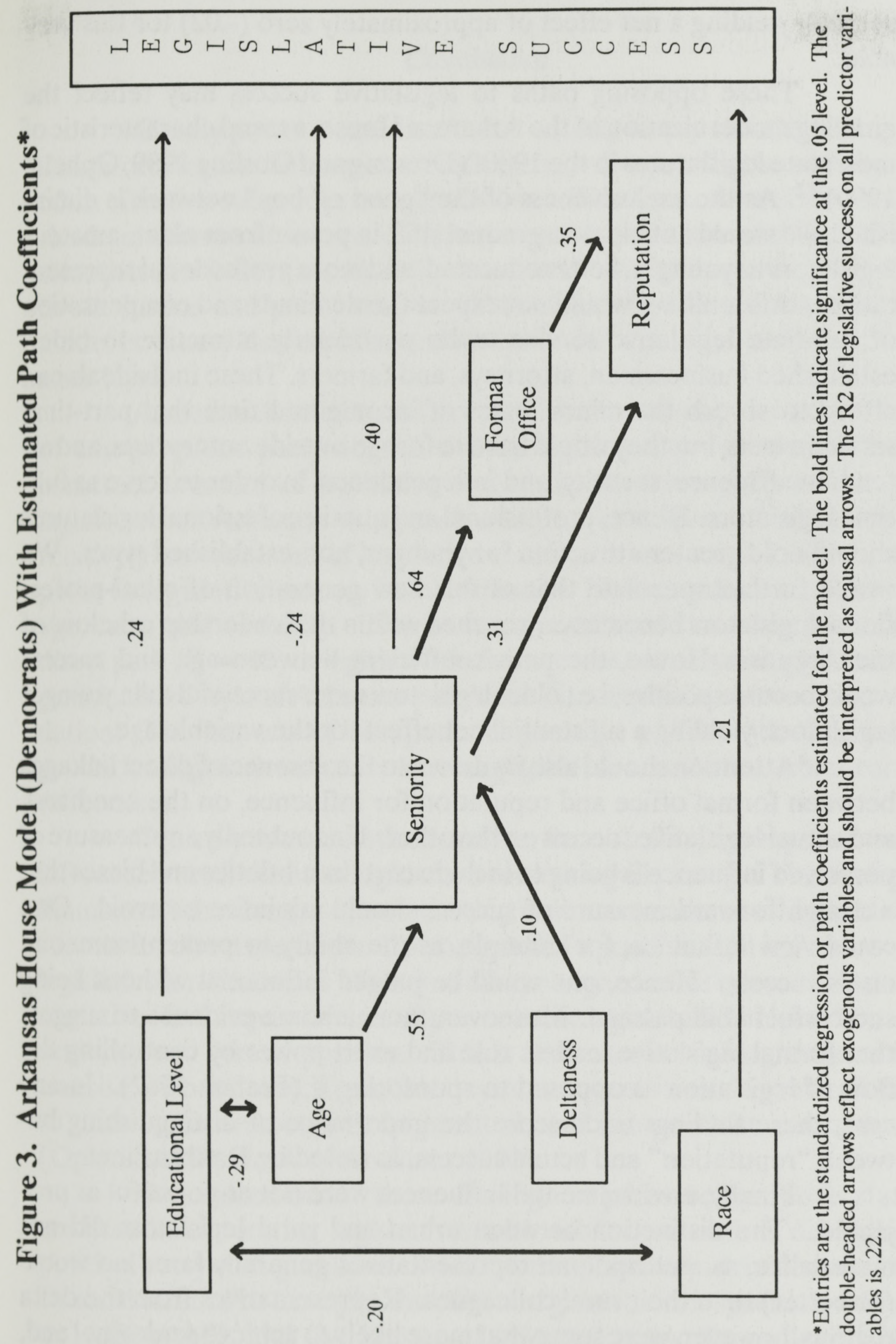


success, yielding a net effect of approximately zero (-.02) for this variable.

These opposing paths to legislative success may reflect the growing modernization of the Arkansas House, a trend characteristic of most state legislatures in the 1980s (Dresang and Gosling 1989; Opheim 1990). ${ }^{12}$ As the exclusiveness of the "good ol' boy" network is diminished, we would anticipate a gradual shift in power from older, amateur legislators to younger, better educated, and more professional representatives. After all, we would not expect the demands and compensation of full-time legislative service to be particularly attractive to older, established businessmen, attorneys, and farmers. These individuals can afford to absorb the minor losses of income and time that part-time service exacts, but they would have to forego outside enterprises, and attendant affluence, security, and independence, in order to serve as fulltime legislators. Hence, professional and quasi-professional legislatures should hold greater attraction for younger, non-established types. We would further speculate that as this new generation of quasi-professional legislators becomes entrenched within the leadership echelons of the Arkansas House, the path coefficient between age and success would become positive, i.e., older legislators more successful than younger legislators, yielding a substantial net effect for the variable age.

Attention should also be drawn to the absence of direct linkages between formal office and reputation for influence, on the one hand, and actual legislative success on the other. Undoubtedly any measure of perceived influence is going to include certain subtleties and biases that a straightforward measure of success should minimize or avoid. One could view influence, for example, as the ability to prevent someone else's success. Hence, one could be judged influential without being successful in bill passage. Moreover, there is some evidence to suggest that formal legislative leaders rule and exert power by controlling the flow of legislation as opposed to sponsoring it (Francis 1962). In any case, these findings underscore the importance of distinguishing between "reputation" and actual success, as noted by Dahl earlier.

Finally, environmental influences were not as powerful as projected. The distinction between urban and rural legislators did not materialize, as metropolitan representatives generally fared no worse (or better) than their rural colleagues. Representatives from the delta regions, however, were somewhat more likely to achieve seniority (and, indirectly, formal position, reputation, and legislative success) than legislators from the non-delta districts. 


\section{Conclusion}

Clearly power is not distributed equally in any state legislature. Therefore, legislative output will reflect the policy proclivities and biases of an effective subgroup, such as that identified here. Identification of the determinants of success and their causal linkages is crucial if political scientists and others are to understand, and ultimately predict, legislative behavior and policy output. Unfortunately, there is no general model or theory that explains and accounts for legislative success at the state level.

Armed with insights and propositions based on previous studies of two-party/one-party dominant state legislatures, we attempted to construct a model of legislative success in the "one party-no party" legislature of Arkansas using path analytic techniques. Employing a relatively new measure of legislative success we ascertained four direct paths to legislative success in the Arkansas House: educational level, age, race, and seniority. That seniority exhibited the most powerful direct path $(\mathrm{B}=.40)$ to legislative influence was not surprising given the personalized style of Arkansas politics and its emphasis upon accommodation. The impacts of occupational prestige, political ideology and gender on legislative success were negligible, as was that of urban-rural differences.

Contrary to expectations, neither formal office nor reputational influence were linked to a legislator's success in bill passage. This finding illuminated the danger of substituting indirect measures of legislative success for direct measures. It also signalled a possible shift in Arkansas' legislative environment. We noted that younger, better educated representatives had acquired bases of power in the legislature independent of seniority and formal position. This is characteristic of legislatures in transition from closed, hierarchical systems rooted in social camaraderie to ones more competitive, fragmented, and independent in structure (Opheim 1990; Book of the States 1990).

Generalization of these findings requires comparative state analyses incorporating legislatures with similar, as well as dissimilar, political party configurations. Additional explanatory variables need to be considered. For example, the effects of gubernatorial position-taking on various bills and the impact of informal networks on legislative success are possible avenues for future inquiry. Finally, longitudinal research designs supported by multivariate procedures are necessary 


\section{Legislative Success}

before any comprehensive model of success in state legislatures can be developed.

\section{NO'TES}

${ }^{1}$ Arkansas has traditionally been among the most one-party dominated of states (Rosenthal 1981, 140; Bibby, Cotter, Gibson, and Huckshorn 1990, 92).

${ }^{2} \mathrm{An}$ effective legislator is loosely defined as one who is relatively successful at navigating his or her bills through the legislative process. A more exact definition is presented later in the paper.

${ }^{3}$ We recognize the dangers of treating ordinal data, such as occupational prestige, formal office, and education, as interval data. However, it has long been recognized that ordinal data can be analyzed by techniques that formally require interval data without any serious distortions (see for example, Bohrnstedt and Carter 1971; Kerlinger and Pedhazur 1973). Also, the literature contains many instances of treating ordinal data as interval for purposes of analysis. For example, Meyer's (1980) causal analysis of the 1973 North Carolina legislature utilized this approach with respect to education, formal office, and occupational prestige. For purposes of comparability, we used virtually the same measurement techniques for these three variables in our analysis of the Arkansas legislature.

${ }^{4}$ Democrats controlled 93 of the 100 seats in the 1981 legislative session of the Arkansas House. (1983).

${ }^{5}$ For a detailed discussion and analysis of this survey see Whistler and Dunn

${ }^{6}$ In measuring legislative effectiveness it was felt that a legislator's "sphere of influence" was limited primarily to the chamber he/she resided in. Consequently, in this study "bill passage" refers to a bill clearing the House chamber and not necessarily to one passed into law.

${ }^{7}$ See Ellickson and Whistler's (1989) study of the Missouri House using a similar method of measuring legislative effectiveness.

${ }^{8}$ Bills submitted by House members and their passage through the five stage process are documented for each legislator in the Arkansas Legislative Digest (1981). A total of 817 individual-sponsored bills were examined and classified using this Five-Point Index. No distinction was made between bills in terms of their substantive importance.

${ }^{9}$ When autocorrelation is present significant tests are more likely to indicate that a coefficient is statistically significant, when in fact it is not. Fortunately, autocorrelation and the problems it presents are more likely to appear with time-series data than with cross-sectional data (as is the case with this study). The only method of reducing the possibility of autocorrelation is to insert into the model as many explicit causal variables as possible. Clearly this approach will ultimately result in an unwieldy theoretical model. Hence the trade-off between erroneous conclusions and a reasonably clear and simple model.

${ }^{10}$ Path analysis is a form of applied multiple regression analysis that uses path diagrams to study the presumed direct and indirect influences of independent variables on each other and on dependent variables. Some of the advantages of this technique include 
permitting the researcher to examine the causal processes underlying his/her observed relationships as well as ascertaining the relative importance of alternative paths of influence for purposes of model building.

${ }^{11}$ Path coefficients are standardized regression coefficients which reflect the average standard deviation change in an effect (endogenous variable) associated with a one standard deviation change in a cause (exogenous variable or preceding endogenous variable), with all other causes of that effect held constant. Path coefficients also allow a comparison of the related magnitudes of the various coefficients within the same model (Asher 1983, 47).

${ }^{12}$ In 1971 the Eagleton Institute of Politics at Rutgers University was commissioned to study the legislative process and procedures within the Arkansas General Assembly and to make recommendations for reform. More than 80 of the 116 recommendations were adopted, resulting in extensive reorganization in 1973. See Craft (1972) for a detailed discussion of this study.

\section{APPENDIX A}

A. Educational Level

$1=$ less than high school diploma

2 = high school diploma

$3=$ some college

$4=$ bachelor's degree

$5=$ master's degree

$6=$ professional degree (e.g., Ph.D.)

B. Occupational Prestige

Occupational prestige was determined by assigning a prestige score from the 1980 census occupational ranking to each legislator's occupation (Stevens and Hoisington 1987).

C. Political Ideology

Political ideology was obtained from a May, 1982 survey of the Arkansas General Assembly members by the Family and God (FLAG) organization. The FLAG survey was converted into a liberal-conservative scale to obtain an average score for each legislator.

D. The demographics of age, race, and gender were determined from the bibliographic write-ups and photographs in the 1981 Arkansas Legislative Digest.

E. Seniority rankings for each legislator were calculated from the number of terms served reported in the 1981 Arkansas Legislative Digest.

F. Formal office was a six-point ordinal scale incorporating both party position and committee position. It assigned the following values to positions: Party Leader or Whip $=5$; Committee Chair and Vice Chair simultaneously on different committees $=4$; Committee Chair only $=3$; two or more Committee Vice Chairs $=$ 2; Committee Vice chair only $=1$; and Member only $=0$ (Meyer 1980, 566).

G. Urban/rural was calculated by dividing the population of the county by its square miles. 
H. Degree of deltaness for a district was determined by the extent of its production of rice and soybeans (neither of which can be raised in the highlands). Data regarding rice and soybean production per district were obtained from USDA publications.

\section{APPENDIX B}

\section{The Five-Point Index}

A score of one was reported if:

$1=$ Bill submitted to initial committee, then withdrawn by sponsor.

$1=$ Bill submitted to initial committee, no further action.

1 = Bill received a "do pass" recommendation from initial committee, no further action.

1 = Bill received a "do pass" recommendation from initial committee, then withdrawn by sponsor.

1 = Bill received a "do pass as amended" recommendation from initial committee, then withdrawn by sponsor.

$1=$ Bill received a "do not pass" recommendation from initial committee, no further action.

$1=$ Bill received a "do not pass" recommendation from the committee, then withdrawn by sponsor.

$1=$ Bill submitted to initial committee, motion to place on calendar failed, no further action.

$1=$ Bill submitted to initial committee, one or more parliamentary maneuvers occurred, bill received a "do pass as amended" or "do not pass" recommendation, no further action.

A score of two was reported if:

2 = Floor amendments in the initial chamber adopted, no further action.

$2=$ Floor amendments in the initial chamber adopted, then bill sent back to committee, no further action.

2 =Floor amendments in the initial chamber adopted, then withdrawn by sponsor.

2 = Floor amendments in the initial chamber adopted, then bill sent back to committee, bill received a "do pass" or "do not pass" recommendation from the committee, no further action.

A score of three was reported if:

3 =Bill was defeated on the floor of the House.

A score of four was reported if:

4 = Bill passed the floor of the House, but encountered "moderate to heavy" formal legislative maneuvering along the way.

NOTE: "Moderate to heavy maneuvering" was when two or more parliamentary maneuvers occurred.

A score of five was reported if:

5 =Bill passed the floor of the House and encountered "little if any" formal

legislative maneuvering along the way.

NOTE: "Little maneuvering" was when one parliamentary maneuver occurred. 